\title{
Cellular Basis of Direct Insulin Action in the Central Nervous System
}

\author{
M. van Houten and B. I. Posner \\ Polypeptide Laboratory, McGill University, Montreal, Quebec, Canada
}

Summary. The in vivo radioautographic method has been applied to elucidate the mechanism of direct peptide hormone "feedback" action in the CNS. Using this method we have identified the circumventricular organs of the brain as general endocrine target tissues for a variety of blood-borne polypeptide hormones, including insulin. In the arcuatemedian eminence region of the hypothalamus bloodborne insulin directly interacts with receptive nerve terminals, suggesting that insulin acts to influence the electrical activity of select hypothalamic nerve circuits at the level of synaptic transmission. Recent results obtained from preliminary surgical and chemical lesion studies of brain indicate that insulin-receptive nerve terminals in the arcuate-median eminence region arise from neurons intrinsic to the medial basal hypothalamus. This has lead us to propose the concept of the hypothalamic tuberoinfundibular insulin-receptive neuron and its axon collaterals as a pathway for the centripetal flow of insulin "signals" in the form of electrical impulses. We envisige that the neuroanatomic pathway, provided by the hypothalamic tuberoinfundibular neuron, functions to link changes in body metabolic activity, as reflected in changing levels of circulating insulin, to the neuronal process of elaborating specific central metabolic-regulatory programs. This pathway could be of key importance in understanding and combating metabolic disease.

Key words: Insulin, insulin receptors, circumventricular organs, hormone feedback

The central nervous system (CNS) organizes patterns of behavior and glandular secretion, and a myriad of autonomic functions into coordinated, integrated programs designed in large measure to satisfy everchanging body nutritional requirements, promote growth and maintain metabolic balance [26-28, 43, 47, 71]. To act appropriately the CNS must have some way of measuring or "sensing" the status of critical body metabolic processes. However, the source or carrier of this information has not been identified. Since specific metabolic events often precipitate the expression of discrete central metabolicregulatory functions, it has been theorized that blood-borne "feedback cues" arise from body metabolic activity to activate the CNS appropriately $[19,22,26,27,33,67,69]$. Polypeptide hormones may act as these cues, since they are intimately involved in tissue metabolic regulation, and their circulating levels often closely reflect different body metabolic states [69]. Furthermore, certain bloodborne polypeptide hormones, such as insulin $[9,11$, $34,54-56,70,72]$, angiotensin II [46] and prolactin [17], have been shown to exert direct effects on specific central regulatory functions. Consequently, it may well be that in addition to their traditional roles in tissue metabolism, blood-borne peptide hormones act as "messengers" alerting the brain to changes in the internal milieu by stimulating specific central regulatory responses.

In order to evaluate the role of insulin or other blood-borne polypeptide hormones as "messengers" linking central metabolic regulatory functions to body metabolic needs, it is critical to determine (a) whether blood-borne polypeptide hormones can interact with the CNS, (b) where the interaction occurs, (c) what neuronal systems are activated by the interaction, (d) how the interaction is translated into a cogent message intelligible to the CNS, (e) how this message is disseminated to the appropriate regulatory "effector" sites in the brain, (f) what central regulatory systems are involved, and (g) what effect 
does alteration in body metabolism have on hormone-to-brain communication.

\section{In Vivo Radioautographic Method for Identifying Receptors for Insulin and Other Blood-Borne Polypeptide Hormones in the CNS}

If a polypeptide hormone acts directly upon central neuronal elements, then such elements must, in accordance with the present view of hormone action [25], possess receptors for the hormone. We have used a procedure involving the in vivo administration of ${ }^{125}$ I-labelled hormones to identify central binding sites for insulin and other polypeptide hormones. Shortly after systemic injection of labelled hormone, perfusion with Ringer lactate solution is begun via an intracardiac cannula, to wash from the vasculature and interstitial fluid unbound radioactivity. This is followed by perfusion with a fixative solution to retain receptor-bound radioactivity for radioautographic visualization and quantitative analysis. Since the intensity of radioautographic reactions reflects the amount of bound radioactivity [23], the difference in reaction intensities obtained following the injection of ${ }^{125}$ I-insulin alone and that obtained following the injection of ${ }^{125} \mathrm{I}$-insulin with excess unlabelled insulin provides, by analogy with the in vitro determination of specific binding [3], an in vivo measurement of specific binding. Using this approach we have localized specific binding sites for bloodborne insulin to two different cellular compartments of the CNS: (a) an endothelial microvessel compartment which is distributed throughout the CNS; and (b) a neuronal compartment which is localized exclusively to the circumventricular organs of the brain.

\section{Insulin Binds to Brain Blood Vessels in Vivo}

Using the in vivo radioautographic approach we have shown that blood vessels throughout the CNS bind blood-borne insulin rapidly and with considerable specificity [59]. The binding of insulin to cerebral microvessels was inhibited by progressively increasing concentrations of coinjected unlabelled insulin, but was unaffected by structurally dissimilar polypeptides. Microvessel binding could explain, at least in part, the presence of insulin receptors in homogenates [21] and subcellular fragments [39] from many different parts of the brain. At the electron microscopic level microvessel endothelium appears to be the cellular site of the insulin receptors (Fig. 1). This has been confirmed using classical in vitro competi- tive analyses of highly purified microvessels isolated from bovine brain (Drs I. Gozes and M. Moskowitz, Laboratory of Neuroendocrine Regulation, Massachusetts Institute of Technology, personal communication).

Direct insulin binding to brain endothelium in vivo is surprising with respect to the traditional view that insulin does not alter directly rates of glucose transport across the blood-brain barrier [31]. However, its importance to human neurophysiology is emphasized by our observation of insulin-specific binding in vivo to microvessels of the primate brain (van Houten, B. Landau, B. I. Posner, unpublished observations). It is possible that insulin plays a role in regulating amino acid transport across the bloodbrain barrier [73], or brain electrolyte balance [2], or that insulin exerts a generalized effect on brain activity by a direct action on another aspect of bloodbrain barrier function perhaps unrelated to glucose uptake. An important corollary to our studies is that the blood-brain barrier physically prohibits direct interaction of blood-borne insulin with neurons in almost all regions of the CNS.

\section{Neuronal Basis of Direct Insulin-Specific Action on the CNS}

\section{Hormone-receptive Role \\ of the Circumventricular Organs}

Within $5 \mathrm{~min}$ of systemic injection insulin penetrates into the circumventricular organs of the brain [60], as these regions do not possess a prohibitive bloodbrain barrier [66]. However, in these regions the binding of ${ }^{125} \mathrm{I}$-insulin was strikingly reduced by coinjected unlabelled insulin (Fig. 2). Detailed study of the median eminence showed that the binding of ${ }^{125} \mathrm{I}$ insulin was blocked by coinjected unlabelled insulin, insulin analogues and structurally dissimilar polypeptide hormones in parallel with their ability to inhibit insulin binding to its receptor in vitro (Fig. 3). Similar observations were obtained in the adjacent hypothalamic arcuate nucleus [60] and in the area postrema (van Houten and Posner, unpublished). These observations indicate that radioautographically visualized binding sites for insulin in the circumventricular organs have the specificity characteristics of biologically important insulin receptors.

\section{Neural Mechanisms of Insulin Action in the Hypothalamus}

Several studies have provided evidence that insulin acts directly on hypothalamic structures, for example after insulin injection directly into the hypothalamus 


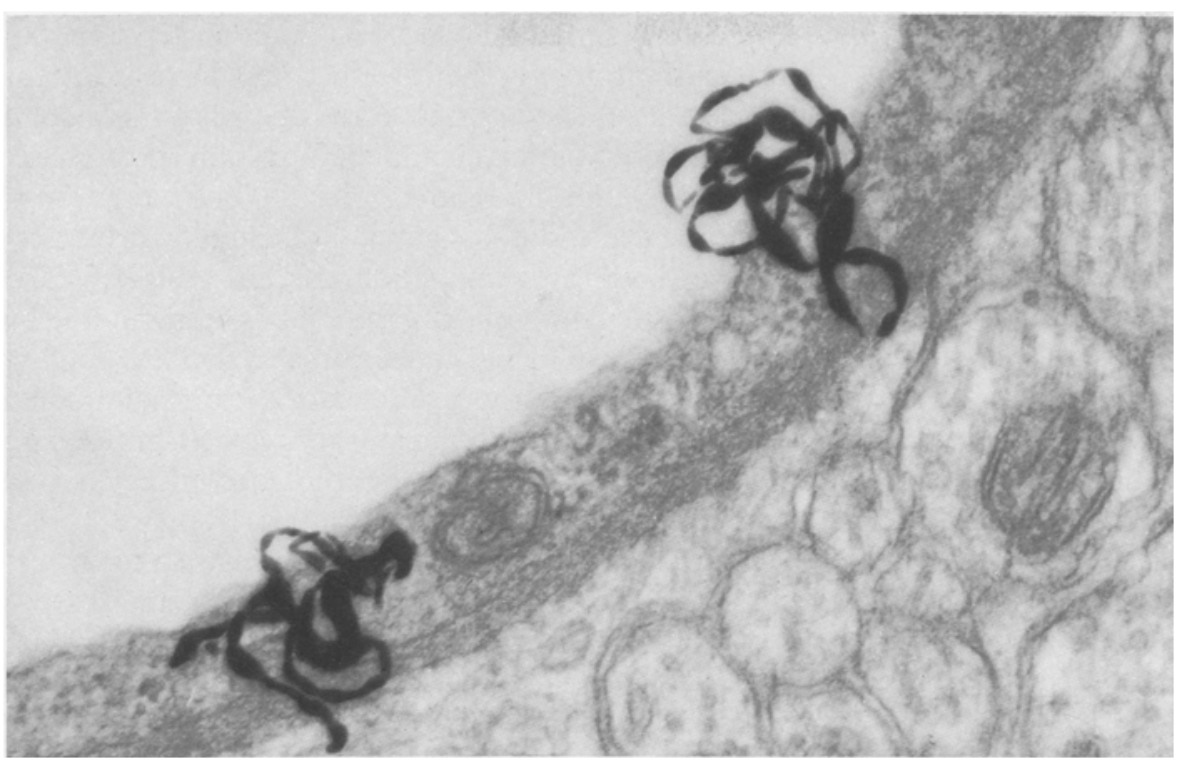

Fig. 1. Electron microscope radioautograph from rat neocortex demonstrating the direct binding of blood-borne ${ }^{125}$ I-insulin to microvessel endothelium. The in vivo radioautographic identification of endothelial insulin receptors may explain in part the widespread distribution of insulin receptors in membrane preparations of brain homogenates $[21,40]$. In vivo radioautographic localization of insulin binding sites over a range of time intervals after systemic injection (van Houten, Posner, unpublished observations) indicates that blood-borne insulin does not directly penetrate the blood-brain barrier (photograph reprinted from van Houten and Posner [59] with kind permission of the editors). $\times 33,000$

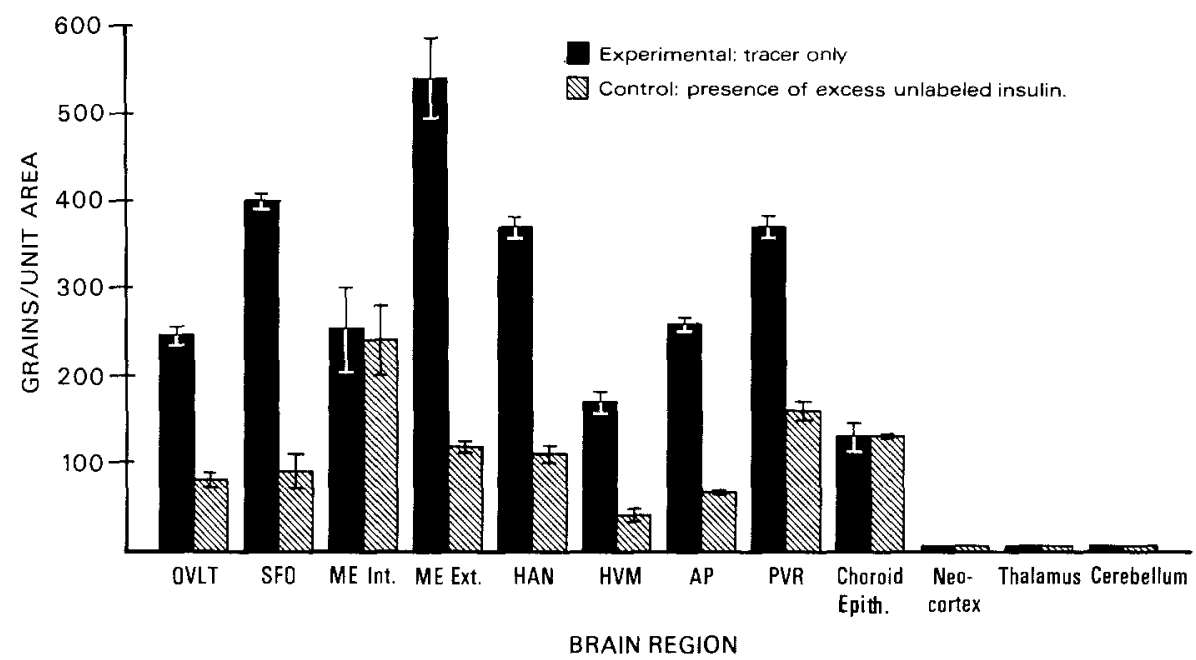

Fig. 2. Regional distribution of specific binding sites for blood-borne ${ }^{125} \mathrm{I}$-insulin as determined by quantitative in vivo light microscope radioautography. The intensity of radioautographic reactions over various regions of the CNS 5 min after intracardiac injection of ${ }^{125} \mathrm{I}$ insulin alone (experimental) or along with a 500 -fold excess of unlabelled insulin (control) is expressed in grains/unit area. Coinjected unlabelled insulin blocked ${ }^{125} \mathrm{I}$-insulin binding to circumventricular structures, namely the organum vasculosum of the lamina terminalis (OVLT), the subfornical organ (SFO), the median eminence external zone (ME Ext.), the hypothalamic arcuate nucleus (HAN), the hypothalamic ventromedial nucleus, pars posterior ventrolateral (HVM), the area postrema (AP) and adjacent paravagal region (PVR). ${ }^{125}$ I-insulin binding to the median eminence internal zone (ME Int.) and the choroid epithelium was unaffected by unlabelled insulin. Grain densities over neuronal parenchyma in all other regions of the CNS, such as neocortex, thalamus and cerebellum, were not different from background, indicating that insulin fails to penetrate the blood-brain barrier. Data refashioned after van Houten et al. [60] 


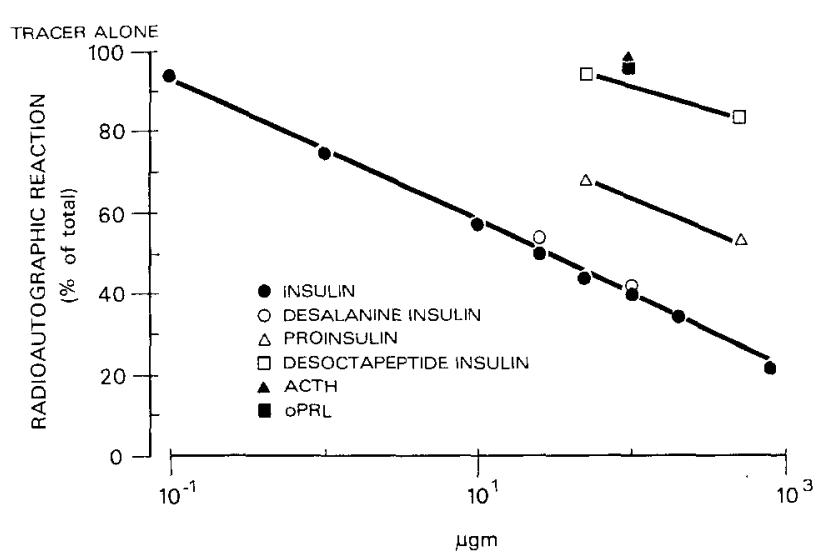

Fig. 3. Quantitative in vivo light microscope radioautographic analysis showed that the binding of blood-borne ${ }^{125}$ I-insulin to the zona externa of the rat median eminence is blocked by coinjected unlabelled insulin, insulin analogues and structurally dissimilar polypeptides in parallel with their ability to inhibit insulin binding to its receptor in vitro [13]. Reaction reductions are plotted as a function of the amount of coinjected unlabelled hormone. Total $(100 \%)$ refers to the reaction intensity obtained following the injection of ${ }^{125} \mathrm{I}$-insulin alone (reprinted from van Houten et al. with kind permission of the editors). Endocrinology 105: 666, 1979

when specific activities are affected. Thus, local insulin injection restores hypothalamic vulnerability to glucose poisoning in diabetic mice [11]. The electrical activity of certain basal hypothalamic neurons is altered when minute amounts of insulin are injected into their immediate environment [38]. Infusion of insulin into the basal hypothalamus activates central glucostatic reflexes [54], suppresses feeding [20] and modifies noradrenergic turnover [34]. Since all but the latter effect have been observed following systemic administration of insulin $[1,10,55]$, cellular elements in the basal hypothalamus, subserving specific metabolic regulatory functions, appear to be directly responsive to blood-borne insulin.

Radioautographically identified specific binding sites for blood-borne insulin in the medial basal hypothalamus [60] may mediate some or all of the insulin effects on basal hypthalamic functions. Thus, high resolution identification of insulin-receptive elements in the median eminence and arcuate nucleus would possibly elucidate a cellular basis for the mechanism of insulin action in this region. Previously [61] in electron microscope radioautographs from rats injected with ${ }^{125} \mathrm{I}$-insulin alone, greater than $80 \%$ of all bound radioactivity visualized in the external median eminence was restricted to neuronal processes, primarily to nerve terminals (Fig. 4 a), but also to pre-terminal axons. Less than one-sixth of the bound radioactivity was localized to glia. In the arcuate nucleus axons and synaptic terminals were most frequently labelled (Fig. $4 \mathrm{~b}-\mathrm{d}$ ). However, in rats coinjected with unlabelled insulin, bound radioactivity resistant to competitive binding inhibition was restricted to glia. Thus, in both regions of the medial basal hypothalamus unlabelled insulin profoundly reduced ${ }^{125} \mathrm{I}$-insulin binding to axons and axon terminals, but exerted no obvious blocking effect on ${ }^{125} \mathrm{I}$ insulin binding to neighbouring glia (Fig. 5). The selective blockade of neuronal ${ }^{125} \mathrm{I}$-insulin binding by unlabelled insulin indicates that the specific binding sites for blood-borne insulin in the external median eminence and arcuate nucleus, previously defined by light microscope radioautography, are in fact associated with axons and their terminals.

The specific interaction of insulin with axon terminals in the external median eminence raises the possibility that blood-borne insulin may stimulate directly the release of hypophysiotropic substances. There is evidence that insulin acts via the basal hypothalamus to directly alter hypophysiotropic control of growth hormone secretion [45]. Axonal and synaptic insulin receptors in the arcuate nucleus seem to be ideally situated to influence synaptic transmission, and thereby bias interneuronal communication and the possible regulatory functions arising from such communication. At either location, however, insulin receptors may mediate local effects of insulin on hypothalamic electrical activity $[1,38]$, and in concert comprise a hypothalamic network of hormone-responsive nerve circuits which directly transform local insulin-receptor interactions into electrical signals influencing central metabolic regulatory functions.

\section{Evidence for a Hypothalamic Tuberoinfundibular System of Insulin-receptive Neurons}

Further elucidation of the neuronal mechanisms of insulin action in the hypothalamus requires complete definition in neuroanatomic and neurochemical terms of the neuronal systems with which bloodborne insulin interacts. This involves the identification of the nerve cells which give rise to the nerve terminals bearing insulin receptors in the median eminence and arcuate nucleus. Precise localization of insulin receptive perikarya will provide a structural basis to elucidate the anatomic pathways over which insulin "signals" are conveyed to the appropriate autonomic and behavioral effector sites in the CNS. We have begun this by employing the in vivo radioautographic approach in combination with various surgical and chemical interventions to define this neuronal system. Our first studies involved the use of the "Halasz knife" [18] to surgically deafferent the medial basal hypothalamus unilaterally from parts of the brain at progressively increasing radii from the 

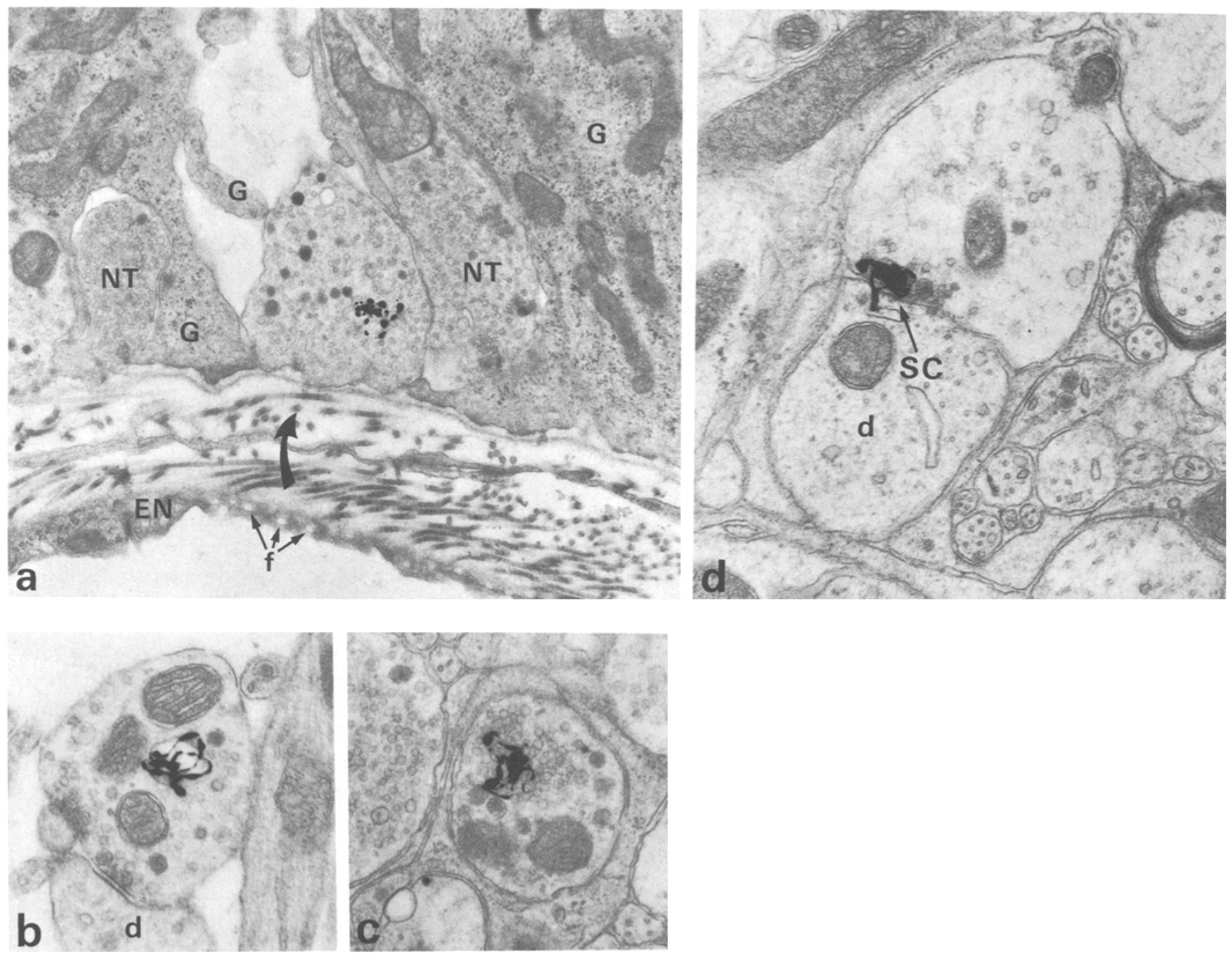

Fig. 4. a Electron microscope radioautograph from tat median eminence demonstrating direct binding of blood-borne ${ }^{125}$ I-insulin to specific sites associated with free nerve terminals. In the centre of the field is a radiolabelled nerve terminal which is surrounded by unlabelled nerve terminals (NT) and glial processes (G). Pores or fenestrae (f) in the endothelial cells (EN) lining the primary capillary plexus of the median eminence permit the rapid translocation of blood-borne insulin, as well as other polypeptides [62, 63, 65], to specific nerve terminal binding sites (bold arrow). $\times 18,000$. b and $\mathbf{c}$ Electron microscope radioautographs from the rat arcuate nucleus showing the direct binding of blood-borne ${ }^{125} \mathrm{I}$-insulin to specific binding sites associated with synaptic terminals. Radiolabelled terminals generally exhibit mixed populations of clear and dense-core vesicles. Often the radiolabel appeared to be closely associated with the vesicle population, suggesting that the insulin-receptor complex has been internalized within the terminal. $d-$ dendritic spine. $\times 24,000 . \mathbf{d}$ Electron microscope radioautograph from the rate arcuate nucleus showing close association of ${ }^{125} \mathrm{I}$-insulin binding sites with vesicle aggregates at the synaptic cleft (SC). Images such as these suggest that insulin acts to alter synaptic transmission possibly via effects on neurotransmitter synthesis or release. $\times 24,000$

arcuate-median eminence region. We reasoned that since the sweep of the knife will sever and thus destroy axonal projections to this region on the affected side of the brain [41], but leave axonal projections on the contralateral side intact, knife cuts that produce a unilateral deficit in insulin binding capacity in the arcuate-median eminence region on the affected side will indicate both the pathway of the insulin-receptive axons toward this region and the distance of the parent perikarya from it. In preliminary unpublished studies (van Houten, Nance, Gauthier, Posner) we found that unilateral cuts through the medial forebrain bundle that deafferent the medial hypothalamus from the rest of the brain do not reduce the insulin binding capacity of the affected side relative to the contralateral intact side. This observation suggests that insulin-receptive axonal processes in the basal hypothalamus are not extrahypothalamic in origin, but rather belong to nerve cells intrinsic to the medial hypothalamus. Thus insulin-receptive axons 


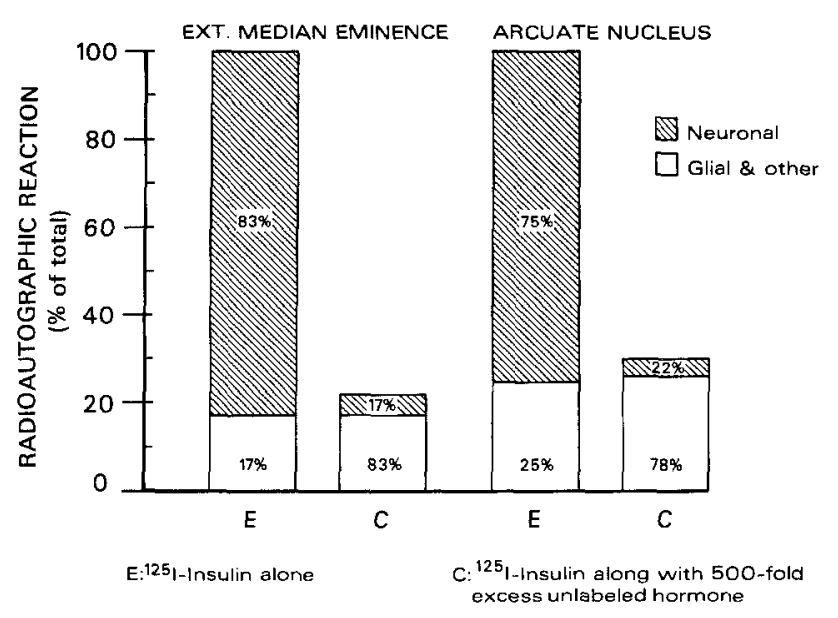

Fig. 5. Selective blockade of ${ }^{125} \mathrm{I}$-insulin binding to neuronal processes in the external median eminence and arcuate nucleus by coinjected unlabelled insulin. The height of the bar indicates the relative light microscope radioautographic reaction intensities obtained following the systemic injection of ${ }^{125} \mathrm{I}$-insulin alone $(100 \%)$ or with a 500 -fold excess of unlabelled insulin (based upon values obtained from van Houten et al., [60]). The bars are subdivided according to the per cent of reaction likely associated with neuronal vs. glial and other structures (based upon values obtained from van Houten et al., [61]). Thus, in the external median eminence of rats injected with ${ }^{125} I$-insulin alone $83 \%$ of all silver grains were localized to axonal processes. A 500 -fold excess of coinjected unlabelled insulin reduced markedly the total ${ }^{125} \mathrm{I}$ insulin binding in this region in light microscope radioautographs. However, electron microscope radioautography showed that $83 \%$ of this residual reaction was localized to non-neuronal elements. Unlabelled insulin blocked selectively ${ }^{125} \mathrm{I}$-insulin binding to neuronal elements, but had no obvious effect on glial binding

may be hypothalamic tuberoinfundibular projections.

Consistent with this possibility are preliminary results of our in vivo radioautographic evaluation of the insulin-specific binding capacity of the medial basal hypothalamus of adult rats treated neonatally with monosodium glutamate (MSG). In treated rats a large portion of the arcuate neuronal population is destroyed early in its development, and thus the median eminence is deficient in terminals arising from arcuate neurons. Axons projecting to the median eminence from nerve cells in other regions of the CNS, however, are unaffected [36]. In adult rats treated neonatally with MSG we have found that the insulin-specific binding capacity of the median eminence and residual arcuate nucleus is reduced in half, suggesting that a sizeable percentage of the insulinreceptive axonal elements in this region arise from tuberoinfundibular arcuate neurons. The fact that developing MSG-treated rats become deficient in growth hormone, stunted in growth and obese [36] suggests that insulin-receptive tuberoinfundibular arcuate neurons are critically involved in the central regulation of growth hormone secretion and body weight during development.

The possibility of a hypothalamic tuberoinfundibular system of insulin-receptive neurons should be considered in light of electrophysiologic evidence that hypothalamic tuberoinfundibular neurons possess multiple axon collaterals which project to numerous sites within the brain, as well as to the median eminence $[48,49]$. These studies have shown that impulses initiated by electrical shocks to the median eminence are propagated antidromically to discrete sites in the hypothalamus and more distant regions of the brain, such as the preoptic area and amygdala, via collateral projections of tuberoinfundibular axons. This aspect of tuberoinfundibular physiology could represent the neuroanatomic pathway over which insulin "signals" are disseminated to specific effector sites deep within the brain. Thus, if electrical impulses are generated by direct binding of blood-borne insulin to receptive terminals in the basal hypothalamus, then it is possible that these electrical impulses could travel via collateral projections to activate specific hypothalamic and extrahypothalamic centers (Fig. 6). By this mechanism the rapid electrical changes in olfactory-related amygdaloid units following systemic administration of insulin [8] may reflect insulin activation of receptive tuberoinfundibular axons with amygdalopetal collaterals.

\section{Does Insulin Act via a GABAergic Mechanism?}

Infusion of insulin into the hypothalamus modifies norepinephrine release only after infusion has ceased [34], suggesting that insulin interacts indirectly with noradrenergic terminals. In our radioautographic studies the inability to hypothalamic deafferentation to reduce the insulin binding capacity of the basal hypothalamus implies that insulin does not directly interact with neurotransmitter systems, such as the brain stem catecholaminergic projection [24], which originate from cells located outside the hypothalamus. Alternatively, it may be that insulin actions are mediated by a class of neurotransmitter produced locally within the medial hypothalamus. Gamma aminobutyric acid (GABA), an inhibitory neurotransmitter synthesized by hypothalamic neurons [57], is one possible candidate for the following reasons:

(1) The GABA content of the medial basal hypothalamus, unlike that for most hypothalamic neurotransmitters, but like the neuronal insulin binding capacity of this region, is unaffected by hypothalamic deafferentation $[41,57]$. Furthermore, the close topographic correspondence of insulin- 


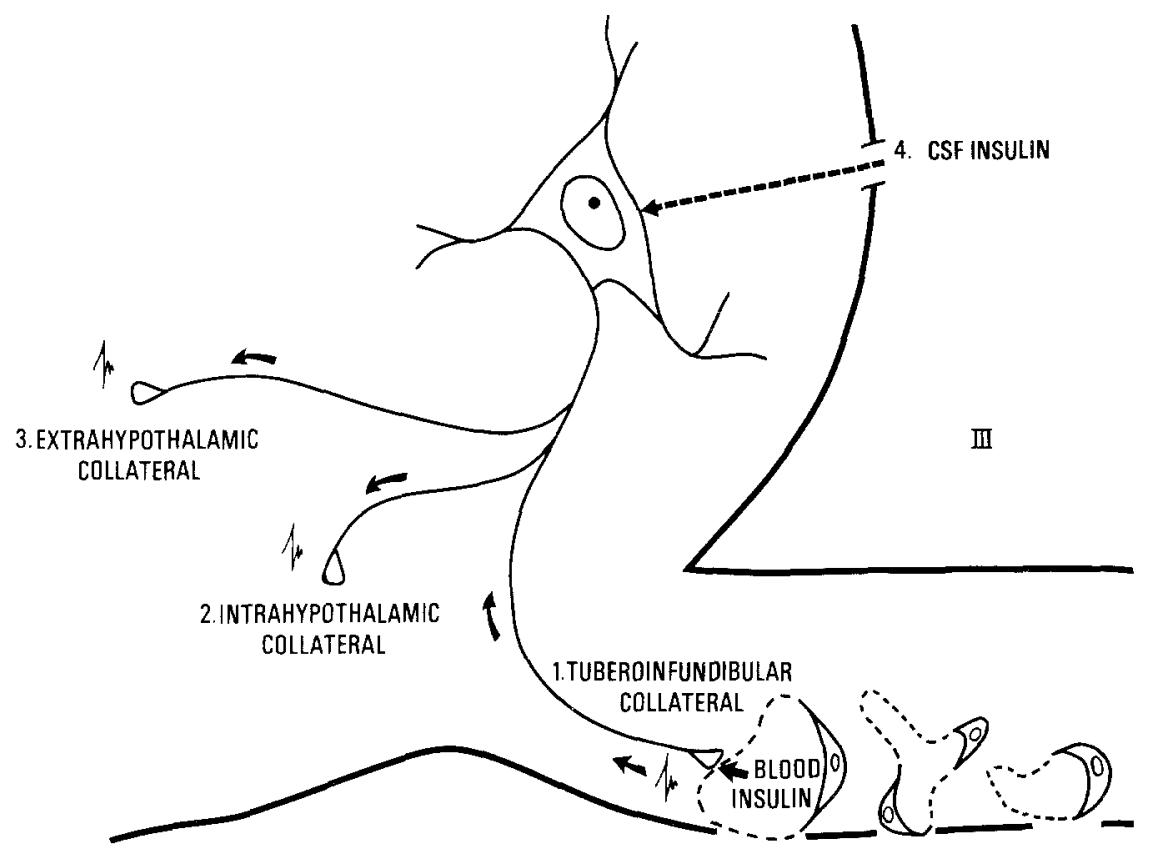

Fig. 6. Diagram illustrating the concept of the hypothalamic tuberoinfundibular insulin-receptive neuron as a pathway for the centripetal flow of insulin "signals" into the CNS. We envisige that the hypothalamic insulin-receptive neuron possesses a large axonal tree with one collateral branch invading the median eminence (1. tuberoinfundibular collateral) and other collateral branches projecting centrally (2. and 3.). Blood-borne insulin passes from the portal circulation through endothelial fenestrae (Fig. 4 a) and binds to a receptive terminal of the tuberoinfundibular collateral. Electrical impulses generated as a result of direct hormone-receptor interaction at the level of the tuberoinfundibular collateral [1] are relayed by intrahypothalamic [2] and extrahypothalamic [3] collaterals to sites behind the blood-brain barrier, where the insulin "signals" participate in the reprogramming of central metabolic-regulatory activities. Via this pathway changes in body metabolic activity, as reflected in changing levels of circulating insulin, could be linked to the neuronal process of determining central metabolic-regulatory responses. Hypothalamic insulin-receptive neurons may also be situated to interact with insulin delivered by diffusion from the cerebrospinal fluid ([4] CSF) $[9,70,72]$. A similar pathway may exist to mediate the effects of other blood-borne polypeptide hormones on receptive terminals in the median eminence $[62,63,65]$. Indeed, hormone-receptive nerve terminals in the median eminencearcuate region may function to concentrate and internalize blood-borne polypeptide hormones so that they can be distributed via axonal transport through collateral branches of the tuberoinfundibular axon to specific sites of action behind the blood-brain barrier

specific binding sites in the rat median eminence and sites of specific GABA uptake in vivo [58] provide a topographic basis for a possible direct action of blood-borne insulin on GABA-ergic terminals.

(2) Blood-borne insulin may directly influence GABA metabolism in the medial basal hypothalamus. In support of this are studies showing that:

(a) levels of GABA in the hypothalamus covary with plasma levels of glucose [30];

(b) ${ }^{14} \mathrm{C}$-glucose is preferentially metabolized to ${ }^{14} \mathrm{C}-\mathrm{GABA}$ in the medial basal hypothalamus [35]; and

(c) blood-borne insulin seems to enhance directly the uptake and metabolism of blood-borne glucose by the medial basal hypothalamus [10, 42], possibly via aerobic pathways [44].

(3) Both insulin [38] and GABA [74] inhibit the electrical activity of medial hypothalamic neurons. Furthermore ventromedial hypothalamic glucoreceptive neurons (known to be insulin-sensitive [38]) exhibit post-excitatory depression during the continuous infusion of glucose [32]. Likewise, certain hypothalamic tuberoinfundibular neurons exhibit a post-excitatory depression possibly mediated by a recurrent inhibitory collateral, which can be partially blocked, by picrotoxin, a GABA antagonist [74].

Thus, it seems plausible to speculate that bloodborne insulin directly activates a hypothalamic network of GABA-ergic nerve terminals, which are functionaliy linked to the local availability of metabolizable glucose as a substrate precursor for neurotransmitter synthesis and release.

\section{Neural Basis of Insulin-specific Action in the Area Postrema}

Light microscope radioautographic studies similar to the studies performed on the median eminence (Fig. 3) indicate that the area postrema contains genuine insulin receptors (van Houten and Posner, 


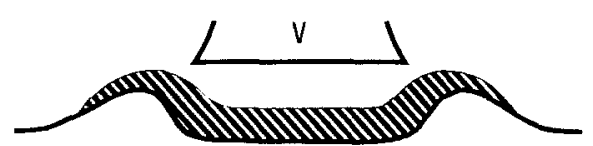

INSULIN
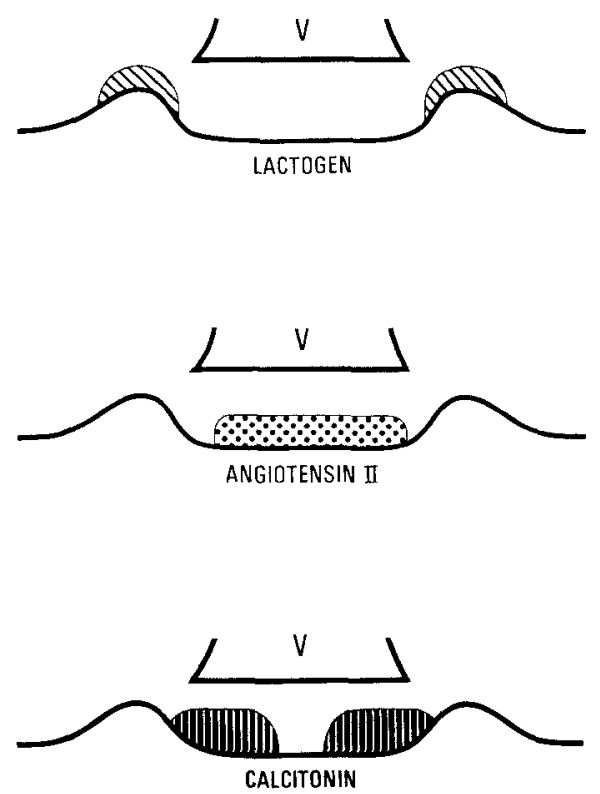

Fig. 7. Comparative topography of specific binding sites for several blood-borne polypeptide hormones in the rat median eminence. Insulin-specific binding sites occur throughout the zona externa and extend into the ventral half of the arcuate nucleus [60]. Lactogen binding sites are concentrated in the lateral palisade zone [62]. Angiotensin $\Pi I$ binding sites are concentrated in the medial palisade zone [63]. Calcitonin binding sites occupy a centrolateral position in the zona externa [65]. These topographic differences in the distribution of hormone-specific binding sites suggest that each peptide hormone interacts with a select class of tuberoinfundibular terminal. This cellular specificity may represent the structural basis for direct peptide hormone effects on discrete central regulatory functions

unpublished observations). Unlike the median eminence, however, the area postrema contains nerve cell bodies as well as axonal processes [66]. In electron microscope radioautographs of rats injected with ${ }^{125}$ I-insulin alone the majority of silver grains were localized to nerve cells, principally dendrites [64]. Two-thirds of all dendrite-associated grains occurred over pockets of cytoplasm containing collections of smooth saccular cisternae, vesicles and multivesicular bodies. Grains within neuronal cell bodies were similarly localized to vacuolar elements associated with the Golgi apparatus. In rats coinjected with unlabelled insulin the density of grains over the area postreama was greatly reduced. These residual grains, representing bound radioactivity not competitively blocked by coinjected unlabelled insulin, were located predominately $(75-80 \%)$ with glia. However, grains over Golgi-associated structures in neuronal perikarya were rare, and dendritic binding was greatly reduced. These results indicate that insulin receptors in the rat area postrema are associated with neurons, and suggest that the hormone-receptor complex, once formed, is rapidly internalized within Golgi-related vacuolar elements of neuronal dendrites and cell bodies.

Specific uptake of ${ }^{125} \mathrm{I}$-insulin and concentration within nerve cell bodies of the area postrema has been confirmed in light microscope radioautographic studies of rat area postrema following intracerebrospinal fluid injection of ${ }^{125} \mathrm{I}$-insulin alone of along with unlabelled insulin (van Houten, Baskin, West, Woods, Posner and Porte, unpublished). Insulin-concentrating neurons, located primarily along the lateral border of the area postrema with the medial solitary nucleus, were observed to retain the radiolabel for at least as long as $48 \mathrm{~h}$ after injection (longer periods were not studied). Thus, unlike insulin receptors in the medial basal hypothalamus, which are associated principally with axonal elements, insulin receptors in the area postrema are associated principally with dendrites, and are rapidly internalized and transported to the parent cell body. These regional differences in the cellular site of insulin binding and subsequent handling by neuronal elements suggest possible regional differences in insulin action.

Neuroanatomical considerations raise the possibility that insulin-receptive nerve terminals in the basal hypothalamus arise from the insulin-concentrating neurons of the area postrema. Studies utilizing axonal anterograde-retrograde transport techniques $[6,50]$ and lesion-degeneration techniques [40] confirm axonal projections from the medial solitary nucleus to the basal hypothalamus. Since certain of the rostrally-projecting axonal systems of the medial solitary nucleus pass through the periventricular brain stem and diencephalon [50], rather than through the medial forebrain bundle, they may not have been eliminated in our initial hypothalamic deafferentation studies. However, published accounts illustrating the location of these neurons [6, 50] do not suggest a close topographic correspondence with insulin-concentrating neurons along the lateral area postrema. The projection field of insulinconcentrating neurons likely involves the adjacent vagal nuclei which are reciprocally connected with the area postrema ( 50 for review). Thus, these receptive neurons may a role in relaying insulin "messages" to this major parasympathetic center. 


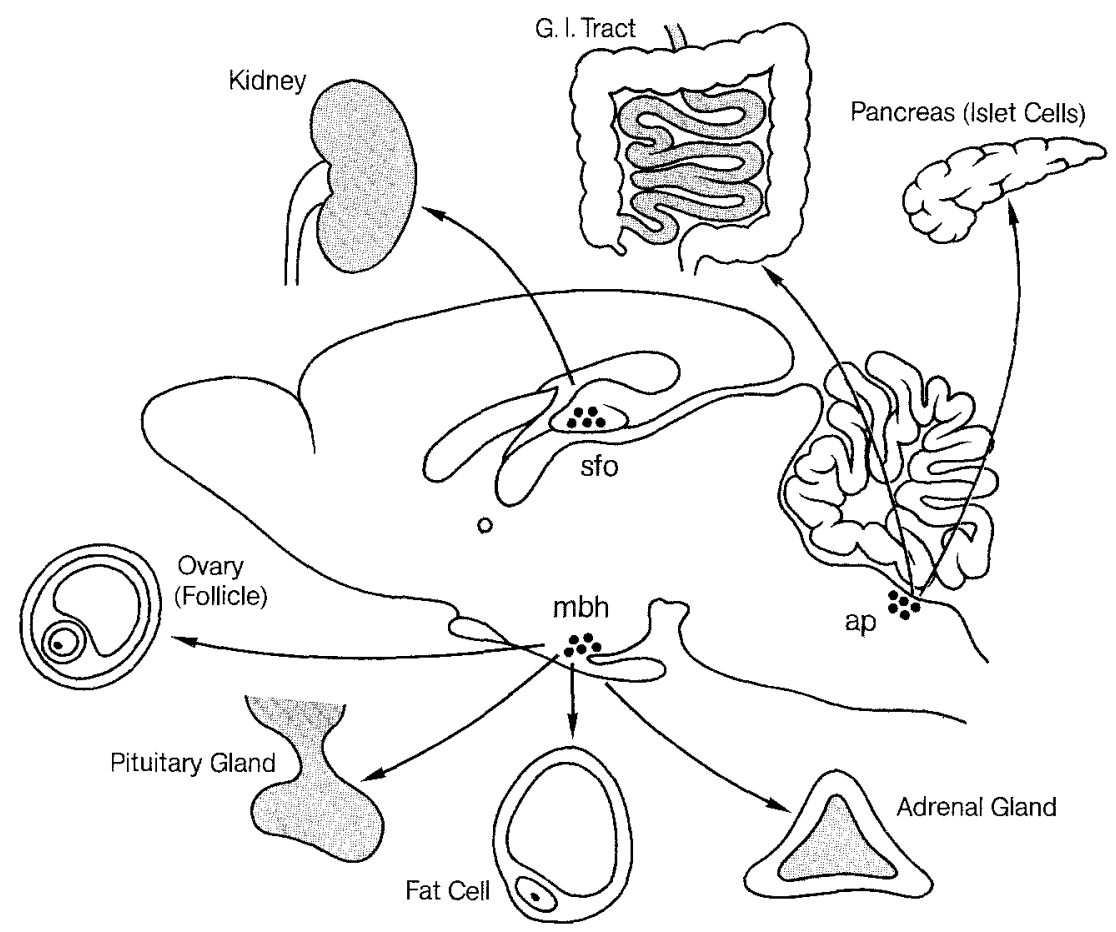

Fig. 8. Diagram illustrating the location of the circumventricular organs, and depicting their functions in simplified form. The medial basal hypothalamus $(\mathrm{MBH})$, containing the median eminence, is involved in regulating rates of glandular secretion, fat deposition and mobilization, and food intake. The subfornical organ (SFO) is linked closely to the regulation of water and salt balance, drinking behaviour, and blood pressure. Functions of the organum vasculosum of the lamina terminalis (OVLT - not shown) are similar to those of the SFO. The area postrema (AG) may be related to vagal functions influencing pancreatic hormone secretion and gastrointestinal-autonomic activity. Specific binding sites for a variety of blood-borne polypeptide hormones occur in all these regions $[62,63,65]$. The role of circumventricular hormone receptors may be to mediate direct feedback effects of blood-borne hormones on the metabolic-regulatory functions subserved by these regions. (reprinted from Diabetes Outlook (oct 1978) vol 13: 8, with kind permission of the editor)

\section{Significance}

\section{The Circumventricular Organs as General Endocrine Target Tissues}

The circumventricular organs, as they are the only regions of the CNS deficient in a prohibitive bloodbrain barrier [66], are therefore the only regions of the CNS where blood-borne polypeptide hormones can interact physically with central neurons. In recently expanding the scope of our studies we have found that the circumventricular organs possess specific binding sites for a variety of blood-borne polypeptide hormones in addition to insulin $[62,63$, 65]. In each instance the blood-borne polypeptide hormone interacts with specific binding sites which are concentrated in discrete subregions of the circumventricular organs (Fig. 7). These additional hormone studies, which further substantiate the validity of the in vivo radioautographic method for identifying hormone-specific binding sites, reveal that the circumventricular organs of the CNS are in fact a new class of general endocrine target tissue. Moreover, our in vivo radioautographic studies with insulin and other blood-borne polypeptide hormones represent the first direct demonstrations of the unique and fundamental importance of the circumventricular organs in hormone-to-brain communication.

\section{Insulin "Feedback" on the CNS in Healthy}

Topographically, the circumventricular organs are situated immediately adjacent to and are neuroanatomically linked with important behavioral and autonomic centers, such as the vagal nuclei, involved in secretomotor regulation $[29,68]$ and taste perception [50], and the medial basal hypothalamus, involved in hypophysiotropic regulation [18] and ingestive behavior [7]. Thus, the intimate neuroanatomical relationship of the circumventricular organs to vital homeostatic centers and the presence of insulin receptors in these regions suggests that circumventricular insulin receptors function to link changes in circulating insulin to the process of elaborating central metabolic-regulatory programs (Fig. 8). For example, rising levels of circulating insulin associated with feeding may act via receptors in the area postrema to stimulate vagal-mediated gas- 
tric secretion [29], and act via receptors in the medial basal hypothalamus to modulate the rate of food consumption [20] and growth hormone secretion [45].

\section{Insulin "Feedback" on the CNS in Disease}

As polypeptide hormones seem to exert effects on specific central metabolic-regulatory functions, and thus may play a key role in coupling central regulatory functions to body metabolic needs, disruption of hormone-to-brain communication could give the CNS an inaccurate picture of the real body nutritional condition. Aberrations in information transfer may result in the inappropriate perturbation of central regulatory systems in a manner or extent counterproductive in satisfying actual metablic needs. For example, the activity of the ventromedial hypothalamus seems to favour hyperglycaemia, in part by tonically suppressing pancreatic insulin output $[4,5,51]$, but also by stimulating hepatic glucose production $[52,53]$ and the secretion of glucagon $[12,15]$, growth hormone [14] and epinephrine [15, 16]. However, insulin seems to inhibit directly the ability of the ventromedial hypothalamus to promote hyperglycaemia, as injection of small amounts of insulin into this region produces hypoglycaemia [54]. Since infusion of insulin into the brain via the carotid artery $[55,56]$ or the cerebrospinal fluid $[9,70]$ also produces hypoglycaemia, insulin delivered by these physiological routes probably acts at a single basal hypothalamic site. If this is true, then reduction in circulating insulin may result in a disinhibition of ventromedial hypothalamic centers promoting hyperglycaemia. Such an occurrance on a chronic basis may contribute to the uncontrolled hyperglycaemia of diabetes mellitus. Thus, defects in the ability of blood-borne polypeptide hormones to guide correctly central regulatory systems could be an important, but as yet unappreciated, factor underlying metabolic and behavioral disturbances. Furthermore, an understanding of hormone-brain interactions could help lead to the development of techniques for mobilizing the vast regulatory capacity of the CNS to combat genetic or acquired metabolic disturbances in human disease.

Acknowledgements. This work was aided by grants from the Canadian Diabetic Association, the MRC of Canada (MT-4182) and the USPHS (1RO1 AM 19573). We thank Dr. S. o. Freedman for support and encouragement.

\section{References}

1. Anand BK, Chhina GS, Sharma KN, Dua S, Singh B (1964) Activity of single neurons in the hypothalamic feeding centers: effect of glucose. Am J Physiol 207: 1146-1154
2. Arieff AI, Doerner T, Zelig H, Massry SG (1974) Mechanisms of seizure and coma in hypoglycemia. Evidence for a direct effect of insulin on electrolyte transport in brain. J Clin Invest 54: 654-663

3. Bergeron JJM, Posner BI (1979) In vivo studies on the initial localization and fate of polypeptide hormone receptors by the technique of quantitative radioautography. J Histochem Cytochem 27: $1512-1515$

4. Bernardis LL, Frohman LA (1971) Effects of hypothalamic lesions at different loci on development of hyperinsulinemia and obesity in the weanling rat. J Comp Neurol 141: 107-115

5. Berthoud H-R, Jeanrenaud B (1979) Acute hyperinsulinemia and its reversal by vagotomy after lesions of the ventromedial hypothalamus in anesthetized rats. Endocrinology 105: 146-151

6. Broadwell RD, Brightman MW (1976) Entry of peroxidase into neurons of the central and peripheral nervous systems from extracerebral and cerebral blood. J Comp Neurol 166: 257-284

7. Brobeck JR, Tepperman J, Long CHN (1943) Experimental hypothalamic hyperphagia in the albino rat. Yale $\mathbf{J}$ Biol Med 15: 831-853

8. Cain DP (1975) Effects of insulin injection on responses of olfactory bulb and amygdaloid single units to odors. Brain Res 99: 69-81

9. Chen M, Woods SC, Porte D Jr (1975) Effect of cerebral intraventricular insulin on pancreatic insulin secretion in the dog. Diabetes 24: 910-914

10. Debons AF, Krimsky I, From A, Clouttier RJ (1969) Rapid effects of insulin on the hypothalamic satiety center. Am $J$ Physiol 217: 1114-1119

11. Debons AF, Krimsky I, From A (1970) A direct action of insulin on the hypothalamic satiety center. Am J Physiol 219: 938-943

12. De Jong A, Strubbe JH, Steffens AB (1977) Hypothalamic influence on insulin and glucagon release in the rat. Am J Physiol 233: E280-288

13. Freychet $P$, Roth J, Neville DM Jr (1971) Insulin receptors in the liver: Specific binding of ${ }^{125} \mathrm{I}$-insulin to the plasmalemma and its relation to insulin bioactivity. Proc Natl Acad Sci USA 68: 1833-1837

14. Frohman LA, Bernardis LL, Kant KJ (1968) Hypothalamic stimulation of growth hormone release. Science 162: 580-582

15. Frohman LA, Bernardis LL (1971) Effect of hypothalamic stimulation on plasma glucose, insulin and glucagon levels. Am J Physiol 221: 1596-1603

16. Frohman LA, Muller EE, Cocchi D (1973) CNS-mediated inhibition of insulin secretion due to 2-deoxyglucose. Horm Metab Res 5: 21-26

17. Fuxe K, Andersson K, Hokfelt T, Agnati LF, Ogren S-O, Eneroth P, Gostafson J-A, Skett P (1978) Prolactin-monoamine interactions in rat brain and their importance in regulation of LH and prolactin secretion. In: Robyn R, Harter $\mathbf{J}$ (eds) Progress in prolactin physiology and pathology. Elsevier North Holland Medical Press, Amsterdam, p 94-109

18. Halasz B, Pupp L (1965) Hormone secretion of anterior pituitary gland after physical interruption of all nervous pathways to the hypophysiotropic area. Endocrinology 77: 533-562

19. Harper AE (1976) Protein and amino acids in regulation of food intake. In: Novins D, Wyrwicka W, Bray G (eds) Hunger: Basic mechanisms and clinical implications. Raven Press, New York, p 103-113

20. Hatfield JS, Millard WJ, Smith CJV (1974) Shortterm influence of intraventromedial hypothalamic administration of insulin in normal and diabetic rats. Pharmacol Biochem Behav 2: $223-226$

21. Havrankova J, Brownstein M, Roth J (1978) Insulin receptors 
are widely distributed in the CNS of the rat. Nature 272 : $827-829$

22. Hoebel GB (1971) Feeding: neural control of intake. Annu Rev Physiol 33: 533-568

23. Junger E (1978) Autoradiographic demonstration of insulin binding sites on cell surfaces. Cytobiologie 18: 250-258

24. Jonsson G, Fuxe K, Hokfelt T (1972) On the catecholaminergic innervation of the hypothalamus with special reference to the median eminence. Brain Res 40: 271-281

25. Kahn CR (1976) Membrane receptors for hormones and neurotransmitters. J Cell Biol 70: 261-286

26. Kennedy GC (1953) The role of depot fat in the hypothalamic control of food intake in the rat. Proc R Soc B 140: 549-553

27. Kennedy GC (1966) Food intake, energy balance and growth. Br Med Bull 22: 216-220

28. Kennedy GC (1969) Interactions between feeding, behavior and hormones during growth. Ann NY Acad Sci 157 : 1049-1061

29. Kerr FWL, Preshaw RM (1969) Secretomotor function of the dorsal motor nucleus of the vagus. J Physiol (Lond) 205: $405-418$

30. Kimura H, Kuriyama K (1975) Distribution of gamma aminobutyric acid (GABA) in the rat hypothalamus: functional correlates of GABA with activity of appetite controlling mechanisms. J Neurochem 24: 903-907

31. Lund-Andersen H (1979) Transport of glucose from blood to brain. Physiol Rev 59: 305-358

32. Marrazzi MA (1976) Hypothalamic glucoreceptor response Biphasic nature of unit potential changes. In: Novin D, Wyrwicka W, Bray G (eds) Hunger: Basic mechanisms and clinical implications. Raven Press, New York, p 171-178

33. Mayer J (1955) Regulation of energy intake and body weight: Glucostatic and lipostatic hypothesis. Ann N Y Acad Sci 63: $15-42$

34. McCaleb ML, Myers RD, Singer G, Willis G (1979) Hypothalamic norepinephrine in the rat during feeding and pushpull perfusion with glucose, 2-DG or insulin. Am J Physiol 236: R 312-321

35. Meeker R, Myers RD (1979) In vivo $\left({ }^{14} \mathrm{C}\right)$ amino acid profiles in discrete hypothalamic regions during push-pull perfusion in the unrestrained rat. Neurosciences 4: 495-506

36. Olney JW, Schwainker B, Rhee V (1976) Chemical lesioning of the hypothalamus as a means of studying neuroendocrine function. In: Sacher EJ (ed) Hormones, behavior and psychopathology. Raven Press, New York, p 153-158

37. Oomura Y, Ooyama H, Yamamoto T, Ono T, Kobayashi N (1969) Behaviour of hypothalamic units during electrophoretic application of drugs. Ann NY Acad Sci 157: 642-665

38. Oomura Y (1976) Significance of glucose, insulin and free fatty acids on the hypothalamic feeding and satiety neurons. In: Novin D, Wyrwicka W, Bray G (eds) Hunger: Basic mechanisms and clinical implications. Raven Press, New York, p 145-157

39. Pacold ST, Blackard WG (1979) Central nervous system insulin receptors in normal and diabetic rats. Endocrinology 105: 1452-1457

40. Palkovits M, Léranth Cs, Zaborszky L, Brownstein MJ (1977) Electron microscope evidence of direct neuronal connections from the lower brain stem to the median eminence. Brain Res 136: 339-344

41. Palkovits M (1979) Effect of surgical deafferentation on the transmitter and hormonal content of the hypothalamus. Neuroendocrinology 29: 140-148

42. Panksepp J (1972) Hypothalamic radioactivity after intragastric glucose- ${ }^{14} \mathrm{C}$ in rats. Am J Physiol 223: 396-401

43. Panksepp J (1974) Hypothalamic regulation of energy balance and feeding behavior. Fed Proc 33: 1150-1 165
44. Panksepp J (1975) Medial and lateral hypothalamic oxygen consumption as a function of age, starvation and glucose administration in rats. Brain Res 94: 133-140

45. Pecile A, Muller EE, Felici M, Netti C (1971) Nervous system participation in growth hormone release from the anterior $\mathrm{pi}$ tuitary gland. In: Pecile A, Muller EE (eds) Growth and growth hormone. Excerpta Medica, Amsterdam, p 261-282

46. Phillips MI (1978) Angiotensin in the brain. Neuroendocrinology $25: 354-377$

47. Powley TL (1977) The VMH syndrome, satiety and a cephalic phase hypothesis. Psychol. Rev 84: 89-126

48. Renaud LP, Martin JB (1975) Electrophysiologic studies of connections of the hypothalamic ventromedial nucleus of the rat: evidence for a role in neuroendocrine regulation. Brain Res 93: 145-151

49. Renaud LP, Martin JB (1976) Tuberoinfundibular neurons in the basomedial hypothalamus of the rat: electrophysiologic evidence for axon collaterals to hypothalamic and extrahypothalamic areas. Brain Res 105: 59-72

50. Ricardo JA, Koh ET (1978) Anatomical evidence of direct projections from the nucleus of the solitary tract to the hypothalamus, amygdala and other forebrain structures in the rat. Brain Res 153: 1-26

51. Rohner F, Dufour A-C, Karakash C, Le Marchand Y, Ruf KB, Jeanrenaud B (1977) Immediate effect of lesion of the ventromedial hypothalamic area upon glucose-induced insulin secretion in anesthetized rats. Diabetologia 13: 239-2412

52. Shimazu T, Fukuda A, Ban T (1966) Reciprocal influence of the ventromedial and lateral hypothalamic nuclei on blood glucose levels and liver glycogen content. Nature 210: 1178-1179

53. Shimazu T, Ogasawara S (1975) Effects of hypothalamic stimulation on gluconeogenesis and glycolysis in rat liver. Am J Physiol 226: 1787-1793

54. Storlien LH, Bellingham WP, Martin GM (1975) Localization of CNS glucoregulatory insulin receptors within the VMH. Brain Res 96: 156-160

55. Szabo O, Szabo AJ (1972) Evidence for an insulin-sensitive receptor in the CNS. Am J Physiol 223: 1349-1353

56. Szabo O, Szabo AJ (1975) Studies on the nature and mode of action of the insulin-sensitive glucoreceptor in the CNS. Diabetes 24: 328-336

57. Tappaz ML, Brownstein MJ (1977) Origin of glutanate decarboxylase (GAD) containing cells in discrete hypothalamic nuclei. Brain Res 132: 95-106

58. Tappaz M, Aguera M, Belin MF, Pujol JF (1980) Autoradiography of gamma aminobutyric acid in the rat median eminence. Brain Res 186: 379-391

59. van Houten M, Posner BI (1979) Insulin binds to brain blood vessels in vivo. Nature 282: 623-625

60. van Houten M, Posner BI, Kopriwa BM, Brawer JR (1979) Insulin binding sites in the rat brain: in vivo localization to the circumventricular organs by quantitative radioautography. Endocrinololgy 105: 666-673

61. van Houten M, Posner BI, Kopriwa BM, Brawer JR (1980) Insulin binding sites localized to nerve terminals in rat median eminence and arcuate nucleus. Science 207: 1081-1083

62. van Houten M, Posner BI, Walsh RJ (1980) Radioautographic identification of lactogen binding sites in the rat median eminence using ${ }^{125}$ I-human growth hormone: evidence for a prolactin "short-loop" feedback site. Exp Brain Res 38: 455-461

63. van Houten M, Schiffrin EL, Mann JFE, Posner BI, Boucher R (1980) Radioautographic localization of specific binding sites for blood-borne angiotensin II in the rat brain. Brain Res 186: $480-485$

64. van Houten M, Posner BI (1980) Brain insulin receptors: radioautographic evidence for rapid internalization within neu- 
rons of the rat area postrema. Endocrine Society Abstracts A 176.8

65. van Houten M., Goltzman D, Posner BI (1980) Brain calcitonin receptors: Localization in normals and deficiency in hereditary diabetes insipidus. Clin Res 28: $676 \mathrm{~A}$

66. Weindl A (1973) Neuroendocrine aspects of the circumventricular organs. In: Ganong WF, Martini L (eds) Frontiers in neuroendocrinology. Oxford Press, New York, p 1-32

67. Wirtschafter D, Davis JD (1977) Body weight: reduction by long-term glycerol treatment. Science 198: 1271-1274

68. Woods SC, Porte D Jr (1974) Neural control of the endocrine pancreas. Physiol Rev 54: 596-619

69. Woods SC, Decke E, Vasselli JR (1974) Metabolic hormones and regulation of body weight. Psychol Rev 81: 126-143

70. Woods SC, Porte D Jr (1975) Effect of intracisternal insulin on plasma glucose and insulin in the dog. Diabetes 24: 905-909

71. Woods SC, Porte D Jr (1978) The CNS, pancreatic hormones, feeding and obesity. In: Advances in metabolic disorders, vol 9. Academic Press, New York, p 283-311
72. Woods SC, Lotter EC, McKay LD, Porte D Jr (1979) Chronic intracerebroventricular infusion of insulin reduces food intake and body weight of baboons. Nature 282: 503-505

73. Wurtman RJ (1976) Control of neurotransmitter synthesis by precursor availability and food consumption. In: Naftolin F, Ryan KJ, Davies $\mathbf{J}$ (eds) Subcellular mechanisms in reproductive neuroendocrinology. Elsevier Publishing Comp, Amsterdam $\mathrm{p}$ 146-166

74. Yagi K, Sawaki Y (1974) Recurrent inhibition and facilitation: Demonstration of the tuberoinfundibular system and effects of strychnine and picrotoxin. Brain Res 84: 155-159

Dr. Mark van Houten

McGill University, Polypeptide Laboratory

Strathcona Medical Bldg., Rm 2-II

3640 University Street

Montreal, PQ H3A2B2

Canada

\section{Discussion after van Houten's Presentation}

Woods: Could you elaborate slightly as to how you are localizing the insulin-receptive neurons in your studies?

van Houten: In recent studies, we performed a unilateral hypothalamic deafferentations using the Halasz knifecut method. Two weeks later, we performed our routine radioautographic experiments reasoning that if the median eminence on the lesioned side is shows reduced binding relative to the control lateral side, we can conclude that some portion of the insulin receptive axons in the median eminence enter through the region of the hypothalamus traversed by the knife cut unimportant. We found that unilateral cuts passing just lateral to the fornix or between the fornix and the ventromedial nucleus did not reduce binding capacity of the median eminence. On the other hand, small electrolytic lesions placed in the center of the arcuate nucleus on one side resulted in a marked reduction of insulin binding capacity of the ipsilateral median eminence. These studies combined implicate the medial basal hypothalamus as the likely site of origin for insulin-receptive nerve terminals in the median eminence. This is consistent with our analysis of the insulin binding capacity of the median eminence from adult rats treated neonatally below with monosodium glutamate. With this technique, as many as 80 or $90 \%$ of arcuate neurons die early in development. The animals become obese and have reduced growth hormone levels. The median eminence area of these rats showed reduced insulin-specific binding.

Fernstrom: Have you done any kind of control to make sure you're not simply damaging the blood supply to the median eminence?

van Houten: The blood supply of the median eminence comes directly from the portal circulation, not the hypothalamus. Our lesions have no effect on this supply and should not compromise it. Further, by using the contralateral side as a control, we have seen no evidence of altered blood supply.
Novin: It seems a very strange nervous system which you contemplate. For if, as you suggest, the receptors are indeed on the axon terminals, retrograde axonal transmission must be occurring to get the message to other terminals.

van Houten: I am suggesting two possible mechanisms by which blood-borne insulin could generate an electrical message in the median eminence-arcuate area, and this message could be disseminated to other regions of brain behind the blood-brain barrier. First, insulin could depolarize receptive nerve terminals occurring in synaptic contact with another neuron. Depolarization resulting in the release of a neurotransmitter could alter the electrical activity of the post-synaptic neuron and its axonal projections. Secondly, insulin could depolarize non-synaptic receptive nerve terminals occurring as free nerve endings in the median eminence. Depolarization could produce an electrical signal which is then propagated antidromically into the brain by retrograde transmission along the parent axon and its collateral projections.

Novin: Is there a precedent for the type of neuron you suggest?

van Houten: Yes, electricophysiological studies demonstrate that electrical shocks are applied to the median eminence, the same signal appears rapidly in both the medical basal hypothalamus and other areas of brain behind the blood-brain burrier, such as the amygdala. Other studies have shown that insulin causes changes of electrical activity within the amygdala within minutes following systemic administration. The rapid time course of these amygdaloid responses to blood-borne insulin could reflect rapid retrograde conduction of impulses generated at receptive terminals in the median eminence and conveyed along axon collaterals to the amygdala. There may be, of course, synaptic interruptions in such a pathway; we are simply postulating a more direct and rapid route. 
Goldman: Have you tried other metabolic models, such as starvation or fasting, or animals with elevated insulin levels?

van Houten: We have done some pilot studies on the ob ob mouse. These animals appear to have normal insulin binding in their circumventricular organs and microvessels.

Oomura: You should be more specific with your terms. You have not actually demonstrated receptors, but only binding sites.

van Houten: You are correct technically, in as far as a biological response capacity is an important criterion of a receptor (6). However, we have demonstrated that insulin binding sites in the median eminence-arcuate area have the specificity characteristics of authentic insulin receptors (Endocrinology 105: 666, 1979). We must look to physiologic studies, such as your own work and that of others, to validate our observations.

Havrankova: Binding sites may or may not have a functional significance.

van Houten: The fact that several groups have found physiological effects of insulin in highly localized regions of the CNS suggests the local presence of functional receptors. We have identified insulin-specific binding sites in these insulin-responsive regions of the brain, and these sites may mediate these responses.

Woods: Does the arcuate area take up intraventricular insulin?

van Houten: A region very near the arcuate nucleus, called the periventricular hypothalamus, takes up radiolabelled insulin from the CSF (van Houten, Barkin, Woods, West, Posner and Porte, in preperation). Binding can be inhibited by co-injection of unlabeled insulin. The specific uptake was largest at $4 \mathrm{~h}$ (our first sampling time) and declined thereafter.

Fernstrom: In these experiments, you may have made the level of insulin in the CSF so high that insulin was forced to penetrate into areas it might not normally reach in significant amounts.

van Houten: Other polypeptides administered intraventricularly show a similar time course of penetration into the periventricular hypothalamus (Neurol (1960) 10: 814, J. Neuropath Exp Neurol (1964) 23: 18), suggesting that the periventricular hypothalamus is normally bathed in CSF-borne peptides. However, our intent was simply to see if additional binding sites could be found by this route of administration. Any physiological significance will have to come later.

Pardridge: In corroboration of your work, we have been using a technique which enables isolation of brain capillaries. We have evidence for a saturable insulin binding system on these capillaries.

van Houten: I understand that Moscowitz at MIT has observed the same thing in the microvessel fraction of bovine cerebrum. It would be of considerable interest to determine what insulin binding sites were left in the brain after the microvessels had been removed.
Porte: On which side of your capillaries were the binding sites?

Pardridge: We couldn't differentiate with this technique. These are membrane preparations, not living cells.

Havrankova: How much non-specific binding did you find?

Pardridge: Around $25 \%$ of the total.

Smith: What role do these receptors play?

Pardridge: Perhaps they facilitate potassium transport; or glycogen formation. There is no indication that they enhance glucose uptake.

Porte: Could you comment on the specificity of the endothelial binding of insulin? Do endothelial cells from other areas of the body bind insulin? Do other peptides bind?

van Houten: Coinjected unlabeled insulin inhibited the binding of ${ }^{125} \mathrm{I}$-insulin to brain microvessels in a dose-dependent fashion, and structurally dissimilar peptides do not block insulin binding (Nature (1979) 282: 623). In related studies, brain microvessels did not bind growth hormone, prolactin, angiotensin, calcitonin, tri-iodothyronine, glucagon, or any other peptide we have tried. We're currently looking at the vascular beds of other tissues, but it's too early to say anything yet. A few years ago, Barr and associates demonstrated that endothelium isolated from human umbilical vein had insulin receptors (J Clin Endo metab (1978) 47: 699).

Havrankova: Yes, but the absolute binding was very low in that study, only 3 or $4 \%$, I believe.

van Houten: Binding was mediated by genuine insulin receptors and that was the crux of the paper.

Berthoud: In your last slide, you had an arrow going to the pancreas, yet you have not talked much about binding in the lower brain stem where vagal efferents arise. Can you comment on this?

van Houten: We have localized specific insulin binding in the area postrema (van Houten and Posner, in preparation). Insulinspecific binding sites occur in association with dendrites and cell bodies. As early as five minutes after systemic injection of ${ }^{125} \mathrm{I}$-insulin, specifically bound radioactivity is internalized within multivesicular bodies and smooth endoplasmic reticulum of target neurons. CSFborne ${ }^{125}$ I-insulin is also concentrated within a small population neurons associated with the area postrema (van Houten, Baskin, Woods, West, Posner, Porte, in preparation). Thus there appears to be a population of area postrema neurons capable of recognizing, internalizing and concentrating both blood-borne and CSF-borne insulin. Perhaps these cells communicate with the adjacent dorsal motor nucleus of the vagus via axonal connections with the nucleus solitarius (J Comp Neurol (1967) 130: 277). The hypothalamic deafferentation studies I spoke of earlier likely eliminate the possibility that insulin-receptive terminals in the median eminence represent rostral projections of the insulin-concentrating neurons of the area postrema.

Pardridge: Have you found insulin binding in the subcommissural organ?

van Houten: No, blood-borne insulin does not penetrate the subcommissural organ which has a blood brain barrier. 